REVISTA DE REVISTAS Y LIBROS

Rev Chil Salud Pública 2020,

Vol 24(2) 169- 172

\section{VIRUS Y SOCIEDAD: HACER DE LA TRAGEDIA SOCIAL, UNA OPORTUNIDAD DE CAMBIOS}

VIRUS AND SOCIETY: TRANSFORMING THE SOCIAL TRAGEDY INTO AN OPPORTUNITY FOR CHANGE
Muy buenas tardes, un saludo a todas y todos los presentes, espero se encuentren muy bien. Primero que nada quisiera agradecer a los responsables de esta edición especial Virus y sociedad: hacer de la tragedia social, una oportunidad de cambios por haber considerado que era necesario generar un número especial que abordara con distintos enfoques y sensibilidades el momento tan crucial por el cual estamos pasando. Este libro con sus diversos capítulos relacionados con la pandemia, quedará como un registro para las actuales y futuras generaciones. Por supuesto quisiera agradecer también a las autoras y autores de los distintos capítulos que entre muchas otras actividades hicieron eco del Ilamado, aceptaron el desafío y encontraron el tiempo para contribuir en este número especial conformado por el prólogo y diez capítulos. Ya me referiré con mayor detalle a ellos, pero antes quisiera felicitarlos por el bello producto obtenido tanto por su contenido como por su estética.

Entrando ya en materia y en la primera parte conformado por seis capítulos, quisiera mencionar que me sorprendió Pandemia por COVID-19: Un hecho social total. Sus efectos sobre la salud mental de los chilenos escrito por los académicos Carlos Madariaga Araya y Ana María Oyarce Pisani. Si bien a estas alturas estamos familiarizados con escuchar respecto al aumento de los efectos en salud mental, en este capítulo se muestra con fuerza la relación con los determinantes sociales y la dificultad que significa encontrar resultados positivos en esta área cuando se ha acumulado una serie de factores de riesgo que no pueden ser revertidos en semanas o meses. Esto potenciado por el neoliberalismo, y acá describo textual una frase de los autores "Con el neoliberalismo se ha logrado producir a escala planetaria una ciudadanía encarcelada en el modelo exitista del emprendedor, cuya expresión final ha sido la de un "emprendedor de sí mismo" fracasado en su fantasía del escalamiento económico: un sujeto deprimido, multisintomático, desesperanzado, anulado como ciudadano". Más allá de lo implacable que resulta leer esa columna, en el capítulo se expone con mucha profundidad las relaciones con distintos determinantes presentes por décadas, que nos han llevado a alcanzar los primeros lugares en rankings de depresión, suicidio y otros y que muestra de qué manera estos determinantes se presentan de manera diferencial en los territorios dando lugar a las inequidades. Se detalla acá los efectos de la pandemia en la salud mental, describiendo a la pandemia como trauma, los efectos clínicos de ésta sobre la salud mental, los efectos psicosociales; y nos detallan también cuales son los grupos más vulnerables destacando la importancia de promover políticas de salud territoriales. En ese sentido los autores dan el ejemplo de la falta de relevancia para algunos sectores de lemas como "quédate en casa" y "lávate las manos", siendo necesario considerar el contexto económico

1 Texto preparado por la Directora y presentado en un conversatorio en línea el 17 de diciembre de 2020. En esta ocación se dió a conocer el libro "Virus y Sociedad: Hacer de la tragedia social una oportunidad de cambios", editado por la Revista Chilena de Salud Pública y disponible en: https://revistasaludpublica.uchile.cl/index.php/RCSP/issue/view/5534 
y de privatización de agua ya que muchos sectores carecen de este preciado bien.

Luego en el capítulo de Memoria Colectiva, Salud Pública y Epidemia por COVID-19 en Chile, 2020, Alvaro Lefio Celedón, Fanny Berlagoscky Mora y Pamela Espinoza Villarroel describen la importancia de la memoria colectiva como vía para comprender los procesos, para vincular pasado y futuro, para dar continuidad, y por otra parte se refieren al olvido y cómo el olvido puede llegar a borrar experiencias. Eso es lo que no queremos que ocurra con esta pandemia, que ojalá pasen muchos años antes que un nuevo evento de esta naturaleza nos vuelva a azotar y que en ese momento tengamos memoria, tengamos registros de lo que ocurrió este 2020. De qué manera esta pandemia afectó los distintos ámbitos de nuestro quehacer y cuales fueron las buenas prácticas que permitieron navegar en este turbulento período. En este sentido el diálogo y reflexión colectiva emergen como una necesidad para una adecuada respuesta. Tenemos una oportunidad de dejarles ese registro a las futuras generaciones y una obligación ética de promover la mejora de las condiciones estructurales que permitan disminuir los riesgos en caso de nuevas experiencias. En este capítulo también los autores hacen un recorrido por los distintos hitos de la pandemia en nuestro país que al igual que en el capítulo denominado Chile frente al SARS-CoV-2: pandemia en medio del conflicto social de los autores María Soledad Martínez, Cristóbal Cuadrado, Matías Goyenechea, Diego Fica y Sebastián Peña nos orientan a través de cifras y fechas sobre los distintos hitos de la pandemia en Chile partiendo por el difícil contexto social en la cual ésta se inició. Una pandemia que fue declarada como tal por OMS tan sólo una semana después que se identificara el primer caso en nuestro país. Sólo dos meses demoró el virus SARs-CoV2 en atravesar el mundo arriba de un avión, sin distinguir límites geográficos, condiciones sociales, económicas, culturales. Con ese record de velocidad, era imposible pensar que una vez en Chile, el virus no se propagaría rápidamente sin distinguir tampoco ninguna condición geográfica o social, mal que mal los 19 millones de habitantes eramos susceptibles en ese momento, sólo un poco menos ahora. Los esfuerzos por contener el avance del virus a través de múltiples estrategias lograron aplanar en algo la curva y así dar tiempo de preparación a los equipos de salud, a que efectivamente pudieran contar con EPP, con la llegada de los "respiradores artificiales" y otras medidas. Desafortunadamente muy tarde se dio la importancia necesaria a APS para la primera estrategia que debió ser considerada: testeo, trazabilidad, y aislamiento. Así las cosas, a mediados de junio nos enfrentábamos con la cifra de 7000 casos diarios por COVID-19, cifra que nos situó nuevamente en los lugares más altos del ranking mundial según el número de casos por cada 100.000 habitantes. De alguna manera tuvimos la oportunidad de tener un deja vu al estar en línea conectados con Europa y Asia, continentes que nos mostraron la película con dos meses de anticipación. En paralelo los países de nuestra región tampoco mostraban resultados más alentadores, todos con distintas estrategias, salvo algunos casos muy puntuales como Uruguay y Costa Rica lograron contar con números más alegres, si es que se puede hablar de números alegres porque la verdad es que un fallecido adicional por esta causa evitable, duele, cuando se le pone nombre, cuando es alguien cercano. Por eso es tan loable el esfuerzo realizado en nuestro país por los equipos de salud, porque una vez más han mostrado su preparación y compromiso. En este capítulo también se refieren a la falla en la comunicación de riesgo y falta de transparencia de los datos como variables importantes que incidieron en la desconfianza de la población en las medidas tomadas por las autoridades.

Esta falla en la comunicación del riesgo también es abordada en el capítulo de Desigualdades sociales y procesos de salud-enfermedad-atención en tiempos de COVID-19: un análisis en clave antropológica desarrollado por Marisol E. Ruiz, Andrea Álvarez Carimoney, María Sol Anigstein Vidal y Ana María Oyarce Pisani, todas ellas pertenecientes al Núcleo de Antropología y Salud, de la Escuela de Salud Pública y Colectivo Crítico Pandemia y Salud. En este capítulo, las autoras se posicionan desde la perspectiva de la antropología de la salud, y de la salud colectiva, con énfasis en la antropología médica crítica. Así, las autoras señalan que "el conocimiento científico es una construcción, y como tal no está ajeno al ensayo y error, y a los intereses de toda clase, puesto que precisamente así es como se produce conocimiento" y agregan "Transparentar las incertidumbres contribuye a sostener una mayor credibilidad en la población, de lo contrario se genera un ambiente de desconfianza que es nocivo para las estrategias de salud pública". También en este capítulo se describe el rol de los determinantes sociales y de qué manera impacta sobre el mayor número de casos y fallecidos y destacan la necesidad de políticas 
participativas para identificar estrategias de abordaje de la pandemia. En este camino la antropología ofrece una mirada para comprender los fenómenos considerando el contexto de los actores/as lo que permite abordar una respuesta adecuada en base a estrategias focalizadas. Más elementos podrán ser revisados en profundidad en este capítulo por los mismos lectores.

En este contexto de ir construyendo también conocimiento en el día a día, comenzaron a emerger otros determinantes que hasta ese momento habían estado menos expuestos hacia la opinión pública. Así comenzamos a conocer antecedentes que son presentados en el capítulo Reflexiones, aprendizajes y desafíos para la salud ambiental en tiempos de pandemia por COVID-19, preparado por académicas y académicos del Programa de Salud Ambiental Karla Yohannessen V., Mauricio Canals L., Dante Cáceres L., Hernán Varas M., Marcelo Villalón C. y Pablo Ruiz R. quienes destacan el concepto "ONE HEALTH" que involucra a la salud humana-animal y ambiental como un sistema único e interconectado que requiere estar en equilibrio. También presentan hallazgos preliminares respecto a estudios en los cuales se ha logrado identificar al virus en material particulado fino y ultrafino reportando que la transmisión aérea constituye una importante vía de transmisión.También en este capítulo los autores abordan nuevos desafíos para los entornos urbanos, y nos muestran cómo en otros países se han implementado medidas en el uso de transportes por ejemplo desde la mirada de sustentabilidad y como una manera para prevenir la propagación del virus. Finalmente y ya en la mirada de formación de recursos humanos especializados en salud pública reflexionan sobre la pertinencia de los planes formativos en la ESP.

Finalizando esta primera parte los autores Yuri Carvajal y Pablo Cox nos ofrecen el capítulo denominado Encerrar y numerar: un accidente tecno-estadístico. Este es un capítulo muy provocador que nos invita a una reflexión interesante respecto esta relación entre los números y lo que ocurre en la realidad. De qué manera intentamos reducir a números fenómenos que van mucho más allá de un caso de enfermedad y muerte y como las estadísticas puede cambiar en la medida que le damos distintas definiciones. Esto ha quedado claramente representado por la definición de muerte por COVID-19. Para mayor claridad describiré un párrafo textual de los autores "el accidente tecno-estadístico ha expresado el carácter profundamente blando de las muertes. Parte de esa blandura es la generación de un espacio propio al virus no sólo en los códigos diagnósticos (U07.1 COVID-19, virus identificado y U07.2 COVID-19, virus no identificado) sino en la asignación de causalidad de las defunciones. Entre los diagnósticos agrupados en la letra $T$ y la $\mathrm{V}$, se ha generado este espacio privilegiado. La definición de la inclusión en la taxonomía respiratoria o infecciosa es una cuestión pendiente, a la que seguramente se agregará la disputa por la falla multistémica o la tormenta inmune como causalidad. El algoritmo humano que venía sosteniendo 10 versiones de la Clasificación Internacional de Enfermedades, asignando una causa única a la defunción y permitiendo una coordinación global de las causas de muertes se ha vuelto frágil y hoy estamos otorgando al COVID 19 el privilegio de ser causa de muerte por su sola presencia en una base de datos de vigilancia (EPIVIGILA). La combinación de dos bases de datos se ha transformado en mecanismo causal". El texto está lleno de este tipo de reflexiones, con información y datos pocos conocidos por un público general, como por ejemplo en una de las secciones en que se refiere al uso de los datos, nos señalan que nuestros datos, esos que ha costado tanto que sean públicos y estén disponibles para las mismas instituciones de salud, académia y otros, están en bases de datos mantenidas por empresas privadas. En fin, los autores nos invitan a revisar ocho temas, entre ellos la epidemiología sin números como un área en que las Escuelas de Salud Pública no hemos puesto suficiente atención.

En la segunda parte del libro, los autores nos invitan a revisar aspectos más específicos. Una mirada a la vejez en tiempos de pandemia desde el enfoque de curso de vida y desigualdades de las académicas Alejandra Fuentes-García y Paulina Osorio-Parraguez de la ESP y Facultad de Ciencias Sociales respectivamente en que las autoras analizan la vejez en el contexto de la pandemia de COVID-19, con un enfoque de curso de vida y de las desigualdades, destacando que estas desigualdades se acentúan en la vejez considerando la posición social y territorial que han tenido las personas mayores en su trayectoria de vida. También presentan el concepto de "viejismo" que se refiere a estereotipos y prejuicios sistemáticos, representados en atributos y características asociados a personas mayores solamente por razones de su edad y que se traducen en acciones de discriminación representadas por ejemplo en una 
limitación de sus derechos adicional al resto de la población, sólo por el hecho de tener cierta edad cronológica. Este hecho es algo sobre lo cual las autoras invitan a reflexionar, cual es la capacidad de "agencia" de los adultos mayores y porqué ellos tendrían que estar subordinados a lo que decidan otros!

La nueva irrupción de las vacunas: a propósito de COVID-19 presentado por Mercedes López, académica del Instituto de Ciencias Biomédicas de la Facultad de Medicina. Este es un tema que está en pleno desarrollo: ustedes han visto que ayer justamente se aprobó el uso de la primera vacuna acá en Chile y esto abre una luz de esperanza para lo que podría ser una de las estrategias que nos permita enfrentar con mayor tranquilidad el desarrollo de la pandemia el 2021. Esto podría ser una "bala de plata de la biomedicina" como se señala en el prólogo, una forma de resolver el problema dejando todo inalterado, ojalá que no, ojalá que quienes estamos en posición de promover y estimular cambios, efectivamente trabajemos en ello.

Finalmente en los últimos dos capítulos: La alimentación en tiempos de pandemia por COVID-19 en que participan Daniel Egaña Rojas, Lorena Rodríguez Osiac y Patricia Gálvez Espinoza, académicos del departamento de atención primaria y la Escuela de Salud Pública respectivamente levantan el problema de la inseguridad alimentaria en Chile y de qué manera COVID-19 ha modificado en distinto grado los ambientes alimentarios. Lo anterior estaría relacionado tanto con problemas de malnutrición por hambre como por el consumo de alimentos de menor calidad nutricional, lo que sería un factor de riesgo para el aumento en la prevalencia de obesidad, especialmente sectores más vulnerables. Por lo anterior, los autores destacan la necesidad de realizar un trabajo intersectorial para enfrentar una posible crisis alimentaria. Esta es un tema que con miras a la nueva constitución también requiere mayor discusión en la agenda pública.

Por último, una colaboración internacional con los académicos Paulo Buss y Sebastián Tobar, ambos del centro de Relaciones Internacionales en Salud de la Fundación Osvaldo Cruz en el tema de Multilateralismo y COVID-19 en América Latina donde los autores describen el papel de las instituciones multilaterales durante esta pandemia y las razones por las cuales se ha presentado un vacío en la cooperación internacional en una región que ya venía muy debilitada económicamente y que se ha convertido en el epicentro de la pandemia. Los autores presentan ideas que mezclan análisis y propuestas con distinto nivel de envergadura.

Como ya sabemos es una pandemia en desarrollo, hemos ido aprendiendo en el camino, el nivel de certezas es menor al que quisiéramos, y nos exige seguir aportando con un trabajo articulado intersectorial, multilateral que permita alcanzar un mayor nivel de bienestar y prevenir nuevos casos y fallecidos.

Reitero el agradecimiento a todos las y los autores y dejo el espacio para las siguientes presentaciones. 